\title{
Whole-body magnetic resonance imaging: an effective and underutilized technique
}

\author{
Ressonância magnética de corpo inteiro: uma técnica eficaz e pouco utilizada
}

\section{Bruno Hochhegger ${ }^{1}$}

Among others, one particular advantage of whole-body magnetic resonance imaging (wbMRI) is the absence of ionizing radiation, a factor that is especially relevant in pediatric imaging, due to the increased sensitivity of children to ionizing radiation. Another important advantage is the high accuracy of the method in the investigation of bone marrow and solid organs, besides the better contrast resolution for soft tissues as compared with other techniques. There is a particular interest in the role played by this method in the field of pediatric oncology (for example, in cases of lymphoma, neuroblastoma, sarcoma and Langerhans' cell disease). Main disadvantages of wbMRI include the relatively long images acquisition time and motion artifacts (requiring patient's cooperation or general anesthesia). However, the developments in computational and imaging techniques, including additional sequences (fat saturation, diffusion-weighted imaging and use of gadolinium enhancement) have reduced the impact of some of these challenges.

An accurate staging and a careful follow-up are essential for patients with neoplastic disease, to evaluate the prognosis and make a decision about the most appropriate therapeutic approach to be adopted. Imaging methods play a fundamental role in such evaluation steps. Computed tomography (CT) and, recently, positron emission tomography (PET/CT) has been widely utilized as an integrated diagnostic approach in cases of systemic cancer ${ }^{(1,2)}$. In particular, up to the present moment, the use of the radiopharmaceutical 18-fluorodeoxyglucose (FDG) has given a relevant contribution in the Field of oncological imaging and has widely been indicated. However, such technique utilizes high ionizing radiation doses and presents some limitations regarding spatial and contrast resolution, besides false negative and false positive results in the evaluation of the skull and upper abdomen, already described in the literature ${ }^{(3)}$. For these reasons, MRI, that is free from ionizing radiation, and presenting high contrast and spatial resolution for soft tissues, is an useful application for detecting and staging malignant tumors and can overcome the limitations of FDG-PET/ $\mathrm{CT}^{(4)}$. In a recent meta-analysis, wbMRI showed to be as effective as PET/CT in oncology ${ }^{(5)}$. This same study suggests that larger prospective studies and, particularly, a cost-effectiveness analysis comparing the methods are necessary to determine which should

1. Professor of Radiology at Universidade Federal de Ciências da Saúde de Porto Alegre (UFCSPA) and at Pontifícia Universidade Católica do Rio Grande do Sul (PUC/ RS), Porto Alegre, RS, Brazil. E-mail: brunohochhegger@gmail.com. be the standard investigation method ${ }^{(\mathbf{5})}$. Even in the assessment of the chest, where only recently MRI has been introduced, several publications show the interest of Brazilian authors, particularly in the area of thoracic oncology ${ }^{(6-16)}$. In pediatrics, due to the absence of radiation, wbMRI has shown unquestionable advantages as compared with PET/CT ${ }^{(\mathbf{1}, \mathbf{6})}$.

Also, it is important to consider the cost of image methods. As a function of the nature and complexity of the imaging system, as well as of the intrinsic maintenance costs, MRI is unavoidably more expensive than CT. However, it is less expensive than PET/CT. Additionally the PET/CT apparatuses include a higher number of components and the demand for a continuous production of radiopharmaceuticals makes it intrinsically more expensive. Owing to the imaging system itself and to the absence of radiopharmaceutical manipulation, MRI is also safer than PET/CT. It was demonstrated that, differently from the ionizing radiation utilized in $\mathrm{CT}$, the powerful magnetic field and the radiofrequency energy of MRI do not cause cancer or fetal abnormalities ${ }^{(\mathbf{1}, \mathbf{6})}$. It is important to observe that, although it is known that CT causes cancer, the exact risk of developing cancer due to exposure to CT or repeated tomographic scans is still to be established ${ }^{(1,6)}$.

In the present issue of Radiologia Brasileira, Teixeira et al. ${ }^{(17)}$ report a very interesting review about wbMRI in pediatrics. The authors reviewed the role played by the method in oncology in the diagnosis and screening for tumors in patients with genetic syndromes; in the evaluation of therapeutic response; and in the post-therapeutic follow-up - as well as in the management of non neoplastic lesions - multifocal osteomyelitis; vascular malformations; and syndromes affecting multiple regions of the body. The mentioned review is an interesting guide for those who want to be familiar with the method and also adds special attention to technical aspects, which represent one of the main obstacles to the dissemination of the technique. Finally, the article demonstrates that, in pediatrics, MRI should soon replace PET/CT considering their similar accuracy level and the absence of ionizing radiation.

\section{REFERENCES}

1. Hochhegger $\mathrm{B}$, Irion $\mathrm{K}$, Marchiori $\mathrm{E}$. Whole-body magnetic resonance imaging: a viable alternative to positron emission tomography/CT in the evaluation of neoplastic diseases. J Bras Pneumol. 2010;36:396.

2. Basu S, Alavi A. Unparalleled contribution of 18 F-FDG PET to medicine over 3 decades. J Nucl Med. 2008;49:17N-21N, 37N.

3. Hochhegger B, Marchiori E, Irion K, et al. Magnetic resonance of the lung: a step forward in the study of lung disease. J Bras Pneumol. 2012;38:105-15.

4. Marchiori E, Ferreira EC, Zanetti G, et al. Whole-body magnetic resonance imaging 
for the evaluation of thoracic involvement in disseminated paracoccidioidomycosis. J Bras Pneumol. 2013;39:248-50.

5. Ciliberto M, Maggi F, Treglia G, et al. Comparison between whole-body MRI and fluorine-18-fluorodeoxyglucose PET or PET/CT in oncology: a systematic review. Radiol Oncol. 2013;47:206-18.

6. Hochhegger B, Marchiori E, Sedlaczek O, et al. MRI in lung cancer: a pictorial essay. Br J Radiol. 2011;84:661-8.

7. Hochhegger B, Marchiori E, Irion K, et al. MRI in assessment of lung cancer. Thorax. 2011;66:357.

8. Marchiori E, Zanetti G, Rodrigues RS, et al. Pleural endometriosis: findings on magnetic resonance imaging. J Bras Pneumol. 2012;38:797-802.

9. Hochhegger B, Marchiori E, Souza LS Jr, et al. Magnetic resonance in N staging of lung cancer. Eur J Radiol. 2013;82:193.

10. Hochhegger B, Marchiori E, Irion K. MRI in lymph node staging of lung cancer. AJR Am J Roentgenol. 2013;200:W540.

11. Guimaraes MD, Schuch A, Hochhegger B, et al. Functional magnetic resonance imaging in oncology: state of the art. Radiol Bras 2014;47:101-11.
12. Guimaraes MD, Hochhegger $B$, Santos MK, et al. Chest MRI in the cancer patient evaluation: state of the art. Radiol Bras. 2015;48:33-42.

13. Guimaraes MD, Gross JL, Chojniak R, et al. MRI-guided biopsy: a valuable procedure alternative to avoid the risks of ionizing radiation from diagnostic imaging methods. Cardiovasc Intervent Radiol. 2014;37:858-60.

14. Guimaraes $M D$, Marchiori $E$, Odisio $B C$, et al. Functional imaging with diffusion weighted MRI for lung biopsy planning: initial experience. World J Surg Oncol. 2014;12:203

15. Guimarães MD, Hochhegger B, Benveniste MFK, et al. Improving CT-guided transthoracic biopsy of mediastinal lesions by diffusion-weighted magnetic resonance imaging. Clinics (Sao Paulo). 2014;69:787-91.

16. Testa ML, Chojniak R, Sene LS, et al. Ressonância magnética com difusão: biomarcador de resposta terapêutica em oncologia. Radiol Bras. 2013;46:17880.

17. Teixeira SR, Elias Jr J, Barbosa MHN, et al. Ressonância magnética de corpo inteiro em pediatria: estado da arte. Radiol Bras. 2015;48:111-20. 